\title{
Transient knockdown and overexpression reveal a developmental role for the zebrafish enosfib gene
}

Steve Finckbeiner ${ }^{1,2}$, Pin-Joe Ko ${ }^{1}$, Blake Carrington ${ }^{3}$, Raman Sood ${ }^{1,3}$, Kenneth Gross ${ }^{4}$, Bruce Dolnick ${ }^{5}$, Janice Sufrin ${ }^{5}$ and Paul Liu'

\begin{abstract}
Background: Despite detailed in vivo knowledge of glycolytic enolases and many bacterial non-enolase members of the superfamily, little is known about the in vivo function of vertebrate non-enolase enolase superfamily members (ENOSF1s). Results of previous studies suggest involvement of the $\beta$ splice form of ENOSF1 in breast and colon cancers. This study used the zebrafish (Danio rerio) as a vertebrate model of ENOSF1 $\beta$ function.

Results: Whole mount in situ hybridization (WISH) showed that zebrafish ENOSF1 $\beta$ (enosf1b) is zygotic and expressed ubiquitously through the first 24 hours post fertilization (hpf). After $24 \mathrm{hpf}$, enosflb expression is restricted to the notochord. Embryos injected with enosf1b-EGFP mRNA grew slower than EGFP mRNA-injected embryos but caught up to the EGFP-injected embryos by $48 \mathrm{hpf}$. Embryos injected with ATG or exon 10 enosfib mRNA-targeting morpholinos had kinked notochords, shortened anterior-posterior axes, and circulatory edema. WISH for $n t l$ or paxza expression showed that embryos injected with either morpholino have deformed notochord and pronephros. TUNEL staining revealed increased apoptosis in the peri-notochord region.

Conclusions: This study is the first report of ENOSF1 function in a vertebrate and shows that ENOSF1 is required for embryonic development. Increased apoptosis following enosfib knockdown suggests a potential survival advantage for increased ENOSF1 $\beta$ expression in human cancers.
\end{abstract}

\section{Background}

Sequence information and computational techniques can be used to group proteins into evolutionarily meaningful families and larger superfamilies. Dayhoff defined protein families as groups of proteins with high $(>50 \%)$ sequence identity [1]. Members of protein superfamilies have lower sequence identities, but statistically significant pairwise alignment scores. Both protein families and protein superfamilies are thought to be monophyletic [1-4]. Since Dayhoff's original work, newer semiautomated classification schemes revealed thousands of protein superfamilies [5,6]. The enolase superfamily (ENOSF), named after the enolase of glycolysis, is used as a model of protein superfamily evolution $[4,7]$. Members of the enolase superfamily share a common ENOSF fold and catalyze a common half reaction: they all abstract protons adjacent to carboxyl groups from a

\footnotetext{
* Correspondence: pliu@mail.nih.gov

'Oncogenesis and Development Section, National Human Genome Research Institute, 49 Convent Drive, Bethesda MD, 20892, USA

Full list of author information is available at the end of the article
}

wide array of substrates. Evolutionarily conserved acidic residues, located in loops at the end of two of the $\beta$ sheets lining the C-terminal barrel of the ENOSF fold, coordinate an essential magnesium and are shared by all ENOSFs. Within the superfamily, different ENOSF families are distinguishable by the identity of the third magnesium ligand and by the different combinations of general acid/base catalytic residues at the ends of the remaining $\beta$ sheets in the $C$-terminal barrel $[4,7]$.

Two of the ENOSF families have representatives in eukaryotes. The ubiquitous glycolytic enolases reversibly dehydrate 2-phosphogylcerate to phosphoenolpyruvate $[7,8]$. Despite being named for mandelate racemase (MR), most members of the MR family with measured enzymatic activities and $\mathrm{x}$-ray structures are acid sugar dehydratases. While many bacterial MR family members have known activities and even $x$-ray structures with bound ligands and inhibitors [9-20], little is known about what roles MR family members perform in eukaryotes. Some fungi have catalytically active MR family members that participate in a sugar metabolizing
C Biomed Central

(c) 2011 Finckbeiner et al; licensee BioMed Central Ltd. This is an Open Access article distributed under the terms of the Creative Commons Attribution License (http://creativecommons.org/licenses/by/2.0), which permits unrestricted use, distribution, and reproduction in any medium, provided the original work is properly cited. 
pathway that allows these fungi to use the sugar rhamnose as a sole carbon source [21,22]. The next best studied group of eukaryotic MR family members are splice isoforms of the human ENOSF1 protein. Human cancer cell lines have three known ENOSF1 splice forms ( $\alpha, \beta$, and $\gamma$ ). Immunoblotting with polyclonal and monoclonal antibodies shows that the $\beta$ isoform (hsENOSF1 $\beta$ ) is the major protein product of the human ENOSF1 locus $[23,24]$. In cell culture, hsENOSF1 $\beta$ expression appears to be regulated by environmental factors such as cell density, time in culture, and exposure to chemotherapy drugs that affect thymidylate synthase or folate pathway enzymes [23-27]. Using patient samples from a Taiwanese population, Kuo et al [28] showed that hsENOSF1 $\beta$ is expressed in breast tumor tissue and not surrounding tissue. The $\alpha$ or $\gamma$ splice forms were not found in the patient samples [28]. The same group also reported a statistically significant decrease in five year survival of colon cancer patients with tumor hsENOSF1 $\beta$ expression compared to colon cancer patients without tumor hsENOSF1 $\beta$ expression [29]. Taken together, in vitro cell culture data [23-27] and human patient data [28,29] suggest a connection between hsENOSF1 $\beta$ expression and cancer.

In this study, we used the zebrafish (Danio rerio) as an in vivo model of ENOSF1 $\beta$ expression. Small adult size, ease of spawning, and rapidly developing glass-clear embryos make zebrafish attractive as a vertebrate model for the study of genes with unknown function. Zebrafish also have a sequenced genome, allowing for easy gene finding and straightforward comparison of zebrafish genes to human genes [30-33]. Building on a previously published bioinformatics study [23], homology searches of the zebrafish genome show that zebrafish have an hsENOSF1 $\beta$ homologue (enosf1b). We show that enosf1b is expressed ubiquitously early in development and is then restricted primarily to notochord after the first 24 hours of development. Phenotypes resulting from enosf $1 b$ knockdown by microinjection of enosf $1 b$-targeted morpholino oligonucleotides provide evidence for enosf1b's involvement in normal development: enosf1bknockdown embryos have deformed notochords. Further characterization with apoptosis and cell cycle markers show that enosf1b-knockdown embryos have increased cell death in the tissues surrounding the notochord, while mitosis appears to be unaffected.

\section{Results}

Phylogenetic analysis reveals a complicated evolutionary history for vertebrate ENOSF1 $\beta$ genes

Protein sequences used in the phylogenetic analysis can be found in Additional file 1. The complete MUSCLE alignment of all full length ENOSF1 $\beta$ homologues is found in Additional File 2. BLASTP searches of NCBI and Ensembl databases followed by MUSCLE alignment and phylogenetic tree construction reveal that the ENOSF1 $\beta$ gene was likely present in the last common ancestor of cephalochordates (Ciona sp, Figure 1) and vertebrates and then lost in different vertebrate classes. The anole (Anolis) has an ENOSF1 $\beta$ while no chicken (Gallus) or zebra finch (Taeniopygia) ENOSF1 $\beta$ homologues were found. With the exception of the guinea pig (Cavia), rodents as an order appear to have lost or are losing their ENOSF1 $\beta$ homologues. The kangaroo rat (Dipodomys) and 13-lined ground squirrel (Spermophilus) have predicted ENOSF1 $\beta$ genes that are missing exons found in other animals. Other sequences with missing exons (Additional file 3) were excluded from MUSCLE alignment and phylogenetic tree construction. While the rabbit (Oryctolagus), guinea pig (Cavia), rat (Rattus), and rhesus monkey (Macaca) genomes are predicted to contain a full length ENOSF1 $\beta$ homologue, their predicted sequences are so divergent that they branch away from their known evolutionary relatives (Figure 1). The mouse, pig, and sheep do not have identifiable ENOSF1 $\beta$ homologue sequences in their genomes.

\section{The zebrafish genome contains one full length homologue of hsENOSF1 $\beta$}

Using hsENOSF1 $\beta$ ([GenBank:NP_059982.2]) as the query sequence, BLASTP searches of the latest version of the zebrafish genome revealed a single full length homologue of human hsENOSF1 $\beta$, [GenBank: NP_001070210.2], which we have named enosf1b. Further bioinformatic searching of the zebrafish genome with Ensembl genome viewer revealed that enosf $1 b$ is located on linkage group 7, base pairs 59,391,419 through 59,891,418 (Figure 2A). The predicted zebrafish ENOSF1 $\beta$ (drENOSF1 $\beta$ ) protein is $71 \%$ identical to hsENOSF1 $\beta$ at the protein level. BLASTP searching of the PDB [34] showed that the closest homologue of hsENOSF1 $\beta$ and drENOSF1 $\beta$ with a solved structure and known biochemical activity is fuconate dehydratase (FucD, [PDB:1YEY]) from the plant pathogenic bacteria Xanthomonas campestris [12]. Alignments of protein sequence with the bl2seq algorithm show that hsENOSF $1 \beta$ and drENOSF $1 \beta$ are $51 \%$ and $54 \%$ identical to FucD, respectively. MUSCLE alignment of hsENOSF1 $\beta$, drENOSF1 $\beta$, and FucD protein sequences (Figure 2B) show that both vertebrate ENOSF1 $\beta$ proteins share residues required for coordinating magnesium and proton abstraction in FucD $[4,7,12]$.

\section{The zebrafish homologue of hsENOSF1 is expressed during development}

Primers located at the first ATG in exon 1 and the 3' end of exon 15 (primers "enosflb full length forward " 


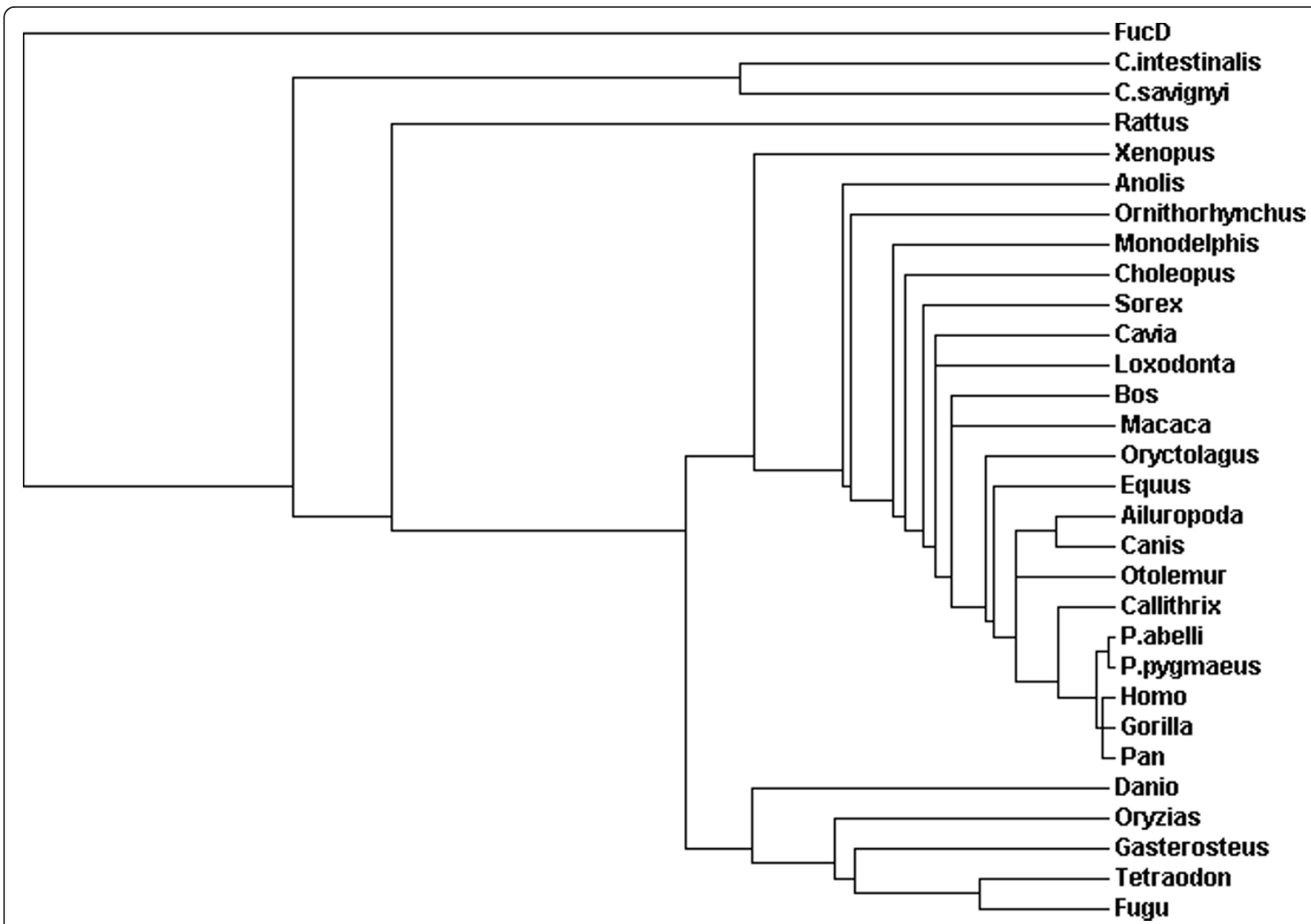

Figure 1 Phylogenetic tree of full length cephalochordate and vertebrate hsENOSF1 $\beta$ homologues. Protein sequences in Additional file 1 were aligned with MUSCLE and a guide tree was constructed automatically. C. intestinalis and C. savignyi are tunicates in the genus Ciona. P. abelli and P. pygmaeus are orang-utans in the genus Pongo.

and "enosf $1 b$ full length reverse", Table 1) were used to amplify enosf $1 b$ cDNA, with pooled RNA from multiple developmental stages. The result shows that enosf $1 b$ is expressed throughout early embryonic development (Figure 3A). Sequencing of the RT-PCR products cloned into pEGFP-N1 (p-enosf1b-N1-EGFP) confirmed the identity of enosflb (data not shown).

WISH performed with enosf $1 b$ antisense probe on zygote through early cleavage stage embryos showed that enosf $1 b$ was zygotic and expressed throughout the early embryo (Figure 3B). Embryos undergoing early somitogenesis (10 somites) ubiquitously expressed enosf $1 b$, while embryos in mid-somitogenesis (16 somites) had stronger expression in tissues such as the eye, somite borders, and notochord (Figure 3B). Ubiquitous enosf $1 b$ expression decreased while notochord enosf $1 b$ expression in 48 to 72 hpf embryos remained (Figure 3C). At $96 \mathrm{hpf}$, there was faint notochord enosf1b (see higher magnification panel in Figure 3C) expression and expression in the pancreas (Figure 3C).

\section{Overexpression of enosf1b-EGFP impairs embryonic} development

Following microinjection of EGFP mRNA, fluorescence was visible throughout the embryos by epiboly and through $48 \mathrm{hpf}$ (Figure 4A-C). Embryos with microinjected enosf1b-EGFP mRNA demonstrated fluorescence only in earlier stages but not at $48 \mathrm{hpf}$ (Figure $4 \mathrm{C}$ ). When embryos were staged at $24 \mathrm{hpf}$, approximately $90 \%$ of uninjected and EGFP-injected embryos were the correct stage. Only $20-40 \%$ of the enosf 1 b-EGFP-injected embryos had reached the 24 hpf stage (Figure 4D, top graphs); suggesting that they were developmentally delayed. This delay was more severe when a higher dose of enosf1b-EGFP was injected (40\% for $60 \mathrm{pg} /$ embryo and $20 \%$ for $180 \mathrm{pg} /$ embryo). When embryos of all three groups were staged at $48 \mathrm{hpf}$, however, the delay had disappeared. Interestingly, the proportionate recovery of correct stage by enosf $1 b$-EGFP-injected embryos at $48 \mathrm{hpf}$ was accompanied by the loss of enosflb-EGFP fluorescence (Figure 4D, bottom graphs), which may 
suggest that overexpressing enosf $1 b$ is not compatible with normal embryonic growth.

Two separate enosf1b-targeting morpholinos generate similar dose-dependent phenotypes

Embryos injected with enosf1b ATG MO at either 3.5 or $7 \mathrm{ng} /$ embryo developed severe developmental defects when compared to uninjected or standard controlinjected embryos. ATG MO-injected embryos had a shortened anterior-posterior axis, pericardial edema, and kinked notochords (Figure 5A). Embryos injected with enosf1b e10i10 MO at the same concentrations developed a similar phenotype, but of lesser severity (Figure 5A). When compared to clutches of embryos injected with 3.5 ng of either MO, clutches of embryos injected with $7 \mathrm{ng}$ of either MO had a higher percentage of embryos with the respective MO phenotypes: the percentage of embryos with either phenotype for the respective $\mathrm{MO}$ is dose dependent (Figure 5B, top panel). Embryos with the phenotype of either MO died by $48 \mathrm{hpf}$.
The e10i10 morpholino causes mis-splicing of enosf1b RT-PCR was used to assay the presence or absence of altered enosf $1 b$ transcripts following injection of the e10i10 MO. Using primers that flank exon 10 (primer sequences in Table 1), PCR of cDNA from individual standard control MO or e10i10 MO-injected embryos (7ng/embryo, all at $48 \mathrm{hpf}$ ) revealed the presence of an additional PCR product $\sim 100 \mathrm{bp}$ longer than the $804 \mathrm{bp}$ expected product (Figure 5C). Sequencing of the longer

\section{Table 1 Oligonucleotide primers used in this study.}

\begin{tabular}{lc}
\hline \multicolumn{1}{c}{ Primer name } & Primer sequence \\
\hline Enosfib full length forward & ATGCTGGCGATCAAAATCATA \\
\hline Enosf1b full length reverse & CTGCTGTTCTCAATGGCTCT \\
\hline Enosfib Xhol Kozak forward & ATACTCGAGGACACCATGCTGGCGATCAAA \\
\hline Enosf1b Sacll reverse & CTCGAGCCGCGGATTTTCTGCTGTTTCTC \\
\hline Exon 10 flanking forward & GCCCTTGTGGAAGCTACTTG \\
\hline Exon 10 flanking reverse & GTGGGGCTTTGAAGTGTC \\
\hline
\end{tabular}




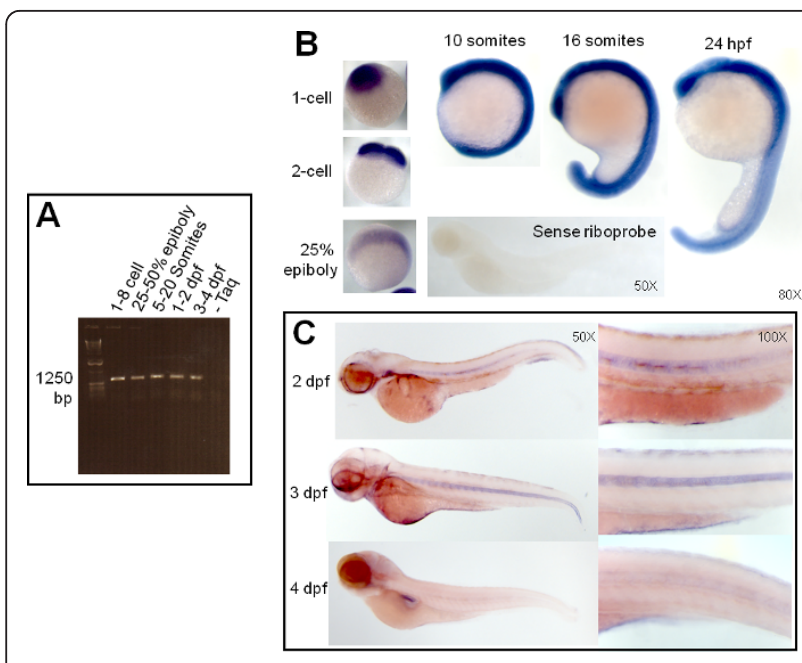

Figure 3 Expression of enosf $1 b$ during development. A: enosfib expression measured by RT-PCR. Primers for full length enosfib (Table 1) were used to test for the presence or absence of enosfib in staged embryo lysate. $\mathrm{Bp}=$ base pairs. B: Whole mount in situ hybridization (WISH) with sense and antisense DIG-labelled riboprobe during early embryonic development. Negative control for WISH, DIG-labelled sense riboprobe, is free of WISH colored precipitate. C: WISH for enosfib during later embryonic development. Except for panel C, original magnification for all photomicrographs is in the lower right hand corner of each picture.

PCR product revealed insertion of intron 10 (Additional file 4). This confirmed the presence of mis-splicing induced by the e10i10 morpholino. As intron 10 contains an even number of base pairs (76 bp), its insertion alters the reading frame of the 3' end of enosf $1 b$ mRNA.

Injecting morpholinos into p53 mutant embryos does not alter the ATG or e10i10 morpholino-induced phenotypes The ATG, e10i10, and standard control MOs (all $7 \mathrm{ng} /$ embryo) were injected into $\mathrm{p} 53^{-/-}$mutant embryos [35] and control wild-type embryos. As shown in Figure $5 \mathrm{~B}$ (bottom panel), there is no statistically significant difference between the percentage of embryos with the ATG or e10i10 phenotype in injected p53 mutant embryos when compared to injected wild type embryos.

\section{The morpholino phenotypes are specific to knock down of enosf $1 b$}

Embryos were injected with enosf1b-EGFP mRNA alone (60 pg/embryo), either ATG or e10i10 MO alone (7 ng/ embryo), or a combination of mRNA and one of the MOs (final concentrations of $60 \mathrm{pg} /$ embryo enosf $1 b$ EGFP mRNA and $7 \mathrm{ng} /$ embryo MO). Figure 5D (left panel) shows that coinjecting enosf1b-EGFP mRNA with the e10i10 MO decreased the percentage of embryos with the e10i10 phenotype. Results of unpaired Student's $\mathrm{t}$ test show that this decrease is statistically significant ( $\mathrm{p}$ value $=0.0380)$. In addition, coinjecting enosf1b-EGFP
mRNA and the ATG MO also decreased the percentage of the embryos with the ATG phenotype (Figure 5D, right panel, $\mathrm{p}=0.0227$ ).

\section{Notochord and pronephros is deformed in both enosf1b morphants}

The notochord phenotype was confirmed by WISH for the notochord-specific transcription factor no tail ( $n t l)$ (Figure 6A, left). While approximately the same diameter and overall length, the notochord in e10i10 and ATG MO-injected embryos is kinked multiple times. The expression of a gene with a wider distribution pattern, $\operatorname{pax} 2 a$, was unaffected in the brain and thymus primordium, slightly reduced in the prospective cranial nerves and eye, but expanded in the pronephros in the ATG morpholino-injected embryos (Figure 6A, right).

\section{Knockdown of enosf1b increases apoptosis but does not change mitosis during zebrafish development}

Results of TUNEL staining show that the area immediately surrounding the notochord had more apoptotic cells in ATG and e10i10 MO-injected embryos when compared to standard control injected and uninjected embryos (Figure 6B-C). On the other hand, antibody staining for a specific marker of mitotic cells, phosphorylated histone $\mathrm{H} 3$, did not change across the different experimental groups (Figure 6B-C).

\section{Discussion}

A previously published phylogenetics study of the ENOSF1 gene [23] found ENOSF1 homologues in all the major phyla except plants. Expanding on these results, we used bioinformatics to find more animal homologues of the ENOSF1 splice form associated with increased cancer risk in human patients: hsENOSF1 $\beta$ $[28,29]$. The overall topology of the ENOSF1 $\beta$ tree (Figure 1) follows the generally accepted model for evolution within chordates [36-40]. Birds apparently lost their ENOSF1 $\beta$ s sometime after the last common ancestor of reptiles and birds (Figure 1). Within the mammalian clade, the branching pattern is dominated more by missing species and rodents that branch within other orders. The rat and guinea pig ENOSF $1 \beta$ s should cluster together with the rabbit ENOSF1 $\beta$ as outgroup. All three sequences should be a sister group to the primates $([36,41]$, but see: $[42,43])$. The missing mouse ENOSF1 $\beta$, the diverged rat ENOSF1 $\beta$, and "normal" ENOSF1 $\beta$ in the guinea pig support the hypothesis that rodents are losing their ENOSF1 $\beta$ genes. This is not as unusual as it may first seem. A recently published study details the loss of the motilin gene and its receptor during rodent evolution [44]. On a broader scale, the work of Hahn and colleagues measures this kind of loss (and gain) across mammalian lineages and entire gene families [45]. 


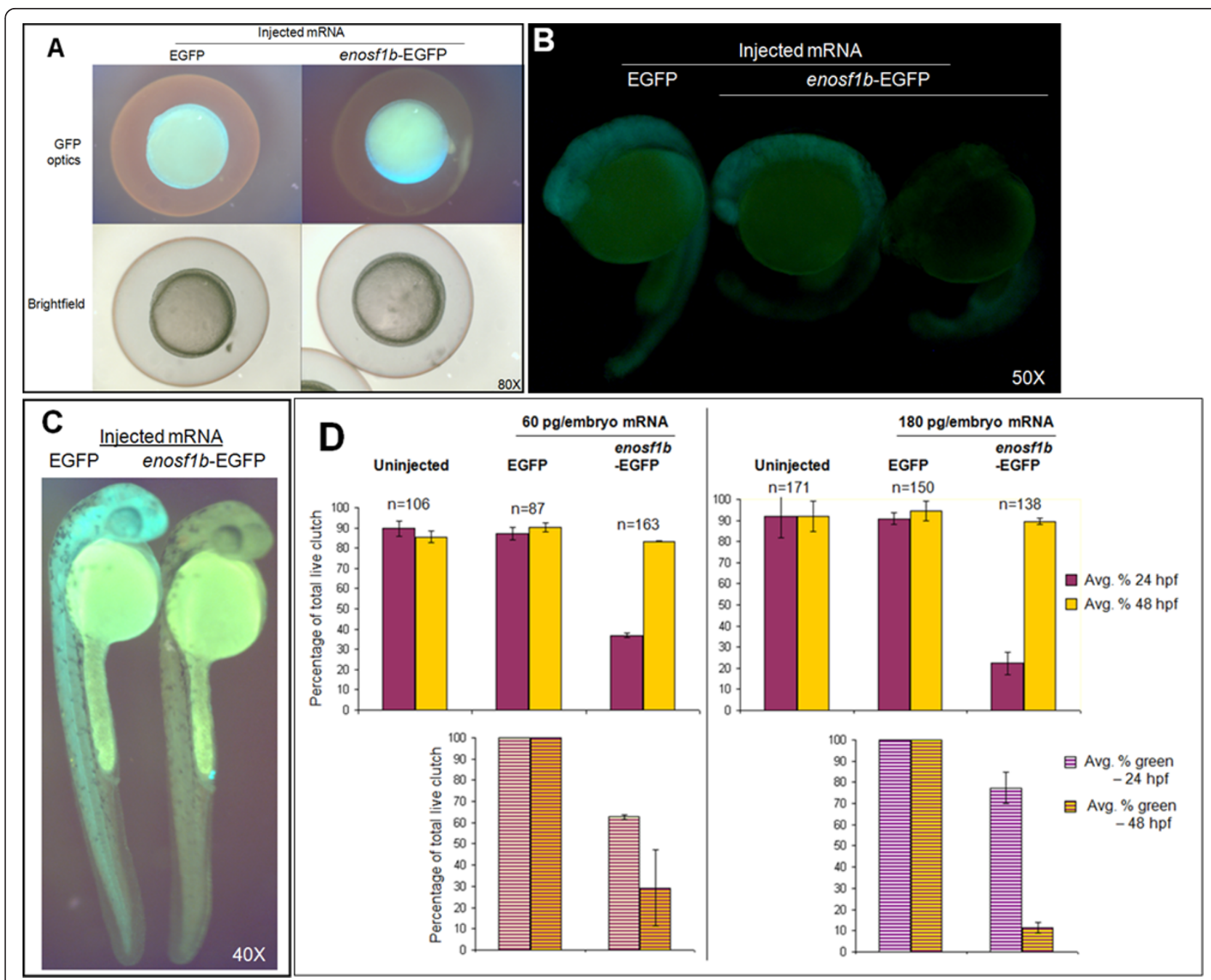

Figure 4 In vivo expression of enosf1b-EGFP compared to EGFP. A-C: Lateral views of representative embryos injected with in vitro transcribed mRNA encoding enosf1b-EGFP or EGFP. Original magnification for all photomicrographs is in the lower right hand corner of each picture. D: Comparison of the effect of injecting equal doses of enosfib-EGFP or EGFP mRNA on time embryos reach 24 hpf or 48 hpf developmental stage. Data is average of three independent experiments; " $n$ " values are total of the three experiments. Error bars are standard deviation. Original magnification for all photomicrographs is in the lower right hand corner of each picture.

Of the vertebrates typically used as model systems with a clearly identifiable genomic ENOSF1 $\beta$, the only diploid species suitable for small scale laboratory work are the zebrafish, Danio rerio, and the frog, Xenopus tropicalis. X. tropicalis has less of the developed molecular biology resources that make zebrafish such a widely used model vertebrate [46]. Homology searches of the zebrafish genome show that zebrafish have a hsENOSF1 $\beta$ homologue (enosf $1 b)$, the protein product of which (drENOSF1 $\beta$ ) is predicted to be $71 \%$ identical to human hsENOSF1 $\beta$. The predicted drENOSF1 $\beta$ has all the key features of the human cancer-associated gene as well as a bacterial gene with a known function: drENOSF $1 \beta$ and hsENOSF1 $\beta$ are both close homologues (slightly > 50\% sequence identity) to the bacterial protein fuconate dehydratase (FucD) and share the conserved residues needed for that enzyme's catalytic activity (Figure 2B) [4,7,12].

Results of RT-PCR and WISH experiments also confirm that enosf $1 b$ is expressed during development (Figure $3 \mathrm{~A}-\mathrm{C})$. The pattern of enosf1b loss during development suggests involvement of drENOSF1 in notochord function [47-49]. It should be noted that there is still faint notochord expression at $4 \mathrm{dpf}$ (see higher magnification inset in $3 \mathrm{C}$ ) that does not photograph well. While it appears that the notochord signal is disappearing, it is possible that the decreased enosf $1 b$ staining is due to lack of probe penetration. Embryos at $4 \mathrm{dpf}$ are beginning to grow skin and are known for having weaker staining of more medial tissues and higher relative viscera staining [50]. 


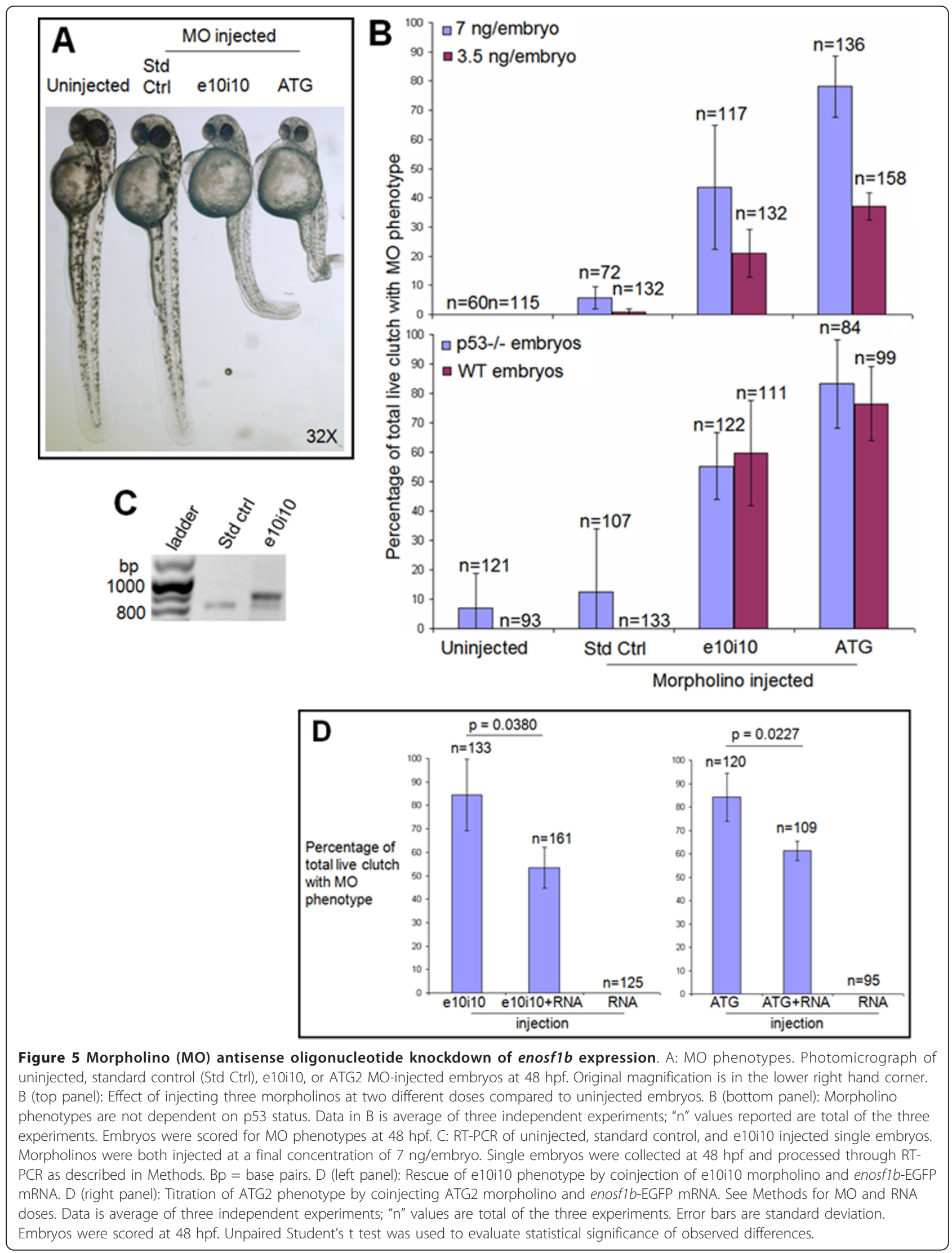




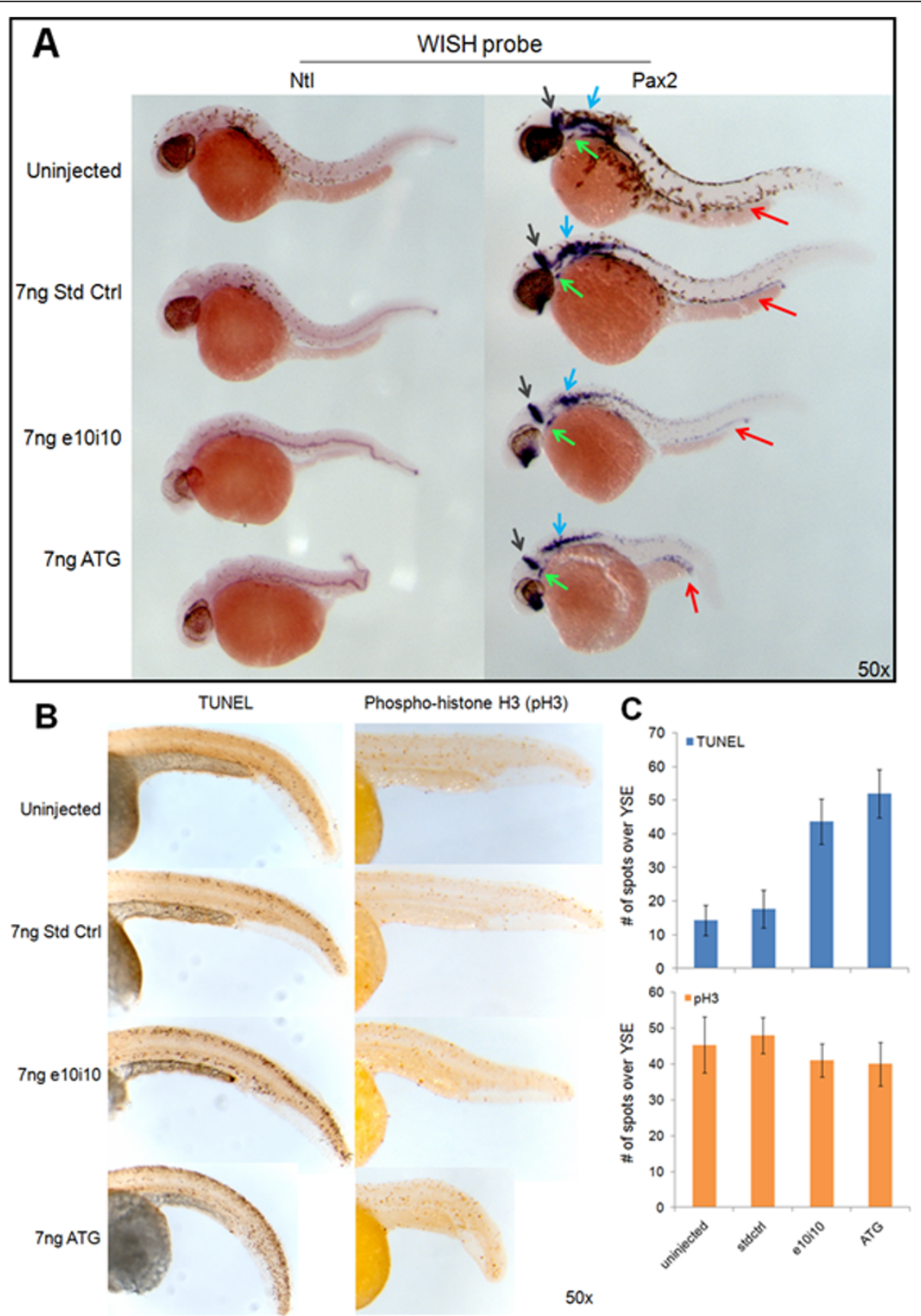

Figure 6 Characterizing the enosf1b knockdown phenotype. A: WISH for no tail and pax2a on 36 hpf morpholino-injected embryos. Red, grey, blue, and green arrows indicate paxza staining of the pronephros, midbrain-hindbrain boundary, prospective cranial nerves, and thyroid primordium respectively. B (left panel): TUNEL staining on uninjected, std ctrl, e10i10, and ATG2 injected 48 hpf embryos. B (right panel): Mitotic index measured in uninjected, std ctrl, e10i10, and ATG2 injected embryos by antibody staining for phospho-histone H3. C: Morpholino-injected embryos have increased TUNEL staining but unchanged pH3 staining. Data is average of 3 tail counts per condition. Error bars are standard deviation. YSE = yolk sac extension. Original magnification for all photomicrographs is in the lower right hand corner of each picture.

Expression of enosf $1 b$ was manipulated during zebrafish development by injecting enosf1b-EGFP mRNA or antisense morpholino oligonucleotides into 1-2 cell stage embryos. Injection of enosf1b-EGFP mRNA into 1-2 cell embryos led to a relatively weak gain-of-function phenotype: developmental delay at $24 \mathrm{hpf}$ (Figure 4A-C). While EGFP-injected embryos were essentially identical to uninjected embryos, significantly fewer enosf1b-EGFPinjected embryos had progressed to the same stage of development as the control embryos. Interestingly, the 
enosf1b-EGFP-injected embryos caught up to the EGFPinjected and uninjected embryos at $48 \mathrm{hpf}$, exactly when the enosf1b-EGFP signal disappeared (Figure 4D). The relatively mild gain-of-function phenotype can be explained by instability of the enosf1b-EGFP mRNA and/ or the enosf1b-EGFP protein [51,52].

Morpholino antisense oligonucleotides were used to generate enosf $1 b$ loss-of-function phenotypes. Multiple lines of evidence show that the knockdown phenotypes observed are specific to enosf1b knockdown. First, two morpholinos that target different evolutionarily conserved regions of the enosf $1 b$ transcript led to similar phenotypes (Additional file 5 and Figure 5A). The second line of evidence supporting the specificity of the observed knockdown phenotypes is provided by RTPCR for enosf $1 b$ following injection of the e10i10 morpholino. Single embryo RT-PCR shows that embryos with the e10i10 phenotype express a longer transcript (Figure 5C). Sequencing the longer product revealed that intron 10 is inserted into the mis-spliced e10i10 transcript (see Additional file 4). Insertion of intron 10 should cause frame shift of the remaining coding sequence. This effectively removes 4 of the 8 evolutionarily conserved catalytic residues (see Figure 2 ). The third line of evidence supporting the enosf $1 b$-specificity of the morpholino phenotypes is provided by the results of injecting the morpholinos into p53 mutant embryos. Some morpholino phenotypes, particularly brain apoptosis, were shown to be caused by a p53-mediated antisense response [53]. The p53 mutant line expresses the full length p53 but has a mutation in the transactivation domain and cannot initiate p53-dependent transcription [35]. Enosf1b-targeting morpholino-injected p53 mutant embryos are indistinguishable from morpholino-injected wild type embryos (Figure 5B, bottom panel). The fourth line of evidence supporting the enosf $1 b$-specificity of the morpholino-induced phenotypes is the results of the mRNA-morpholino coinjection, or rescue, experiments. Coinjecting enosf $1 b$ and either of the two morpholinos "rescues" or decreases the morpholino-induced phenotype (Figures 5D).

The most striking visibly observable characteristic of both morpholino-induced phenotypes is the kinked notochord. WISH shows that enosf1b is strongly expressed in notochord between late somitogenesis and 48 hpf. WISH for a notochord-specific gene, no tail [54], clearly highlights the severely deformed notochord in enosf1b morpholino knockdown embryos (Figure 6A). The salient feature of the knockdown phenotypes produced by different anti-enosf1b, a kinked notochord by $48 \mathrm{hpf}$, is precisely where and when enosf $1 b$ is highly expressed. WISH for $\operatorname{Pax} 2 a$ [55] was also performed. $\operatorname{Pax} 2 a$ is a transcription factor that is involved in development of the eye, brain, cranial neurons, thyroid primordium, and pronephros. The WISH data for pax2a suggests that enosf $1 b$ is involved in the normal development of some of those tissues.

Other assays performed on anti-enosf $1 b$ morpholinoinjected embryos also reveal changes in the peri-notochord tissues. When compared to standard control injected or uninjected embryos, anti-enosf1b morpholino-injected embryos have increased TUNEL staining [56] in the peri-notochord tissues. The increased apoptosis is apparently not dependent on a stalled cell cycle. Whole mount antibody staining for an accepted proliferation marker, phospho-histone $\mathrm{H} 3$ ( $\mathrm{pH} 3$ ) shows that there is no visible change in the cell cycle in enosf1bknockdown embryos (Figure 6B). Experimental embryos had equivalent pH3 staining, indicating no change in achieving $\mathrm{M}$-phase. The TUNEL and phospho-histone $\mathrm{H} 3$ ( $\mathrm{pH} 3$ ) results for uninjected embryos shown in Figure $6 \mathrm{~B}$ are similar to TUNEL results reported elsewhere $[56,57]$. Additional support for a cell cycle-independent increase in apoptosis is provided by the previously described p53-independence of the morpholino-induced phenotypes (Figure 5B, bottom panel). Increased apoptosis following enosf1b knockdown is especially interesting given the recent clinical studies implicating human ENOSF1 $\beta$ as a risk factor for two separate cancers $[28,29]$. Perhaps increased ENOSF1 $\beta$ confers a survival advantage on tumour cells by interfering with apoptosis [58-61].

The increased apoptosis is limited to the area around the notochord (see especially e10i10 panel in Figure 6B). There are two possible explanations for this change. First, enosf1b could be involved in production of a prosurvival signal or consumption of a pro-death signal by the notochord. When enosf1b-targeting morpholinos are injected, enosf $1 b$ decreases and the pro-survival signal disappears or the pro-death signal increases, leading to increased apoptosis. This idea fits with previous discovery of a soluble signal produced by hsENOSF1 $\beta$-overexpressing drug resistant cancer cells [62] and the known signalling role of the notochord. In addition to providing structural support for the developing embryo, the notochord secretes soluble signalling proteins like hedgehog which is known to be involved in inducing formation of the ventral neural tube $[49,63]$. Notochord-produced hedgehog probably also plays a role in somite differentiation and inhibition of cardiac mesoderm fate in paraxial mesoderm. Removing the notochord, or interfering with hedgehog signalling, also interferes with pancreas development $[48,49]$. In addition to hedgehog, notochords of different species are known to secrete many soluble proteins and growth factors like BMPs, TGF $\beta$ s, and FGFs $[47,49]$. A simpler but no less interesting possibility can explain the increased peri-notochord increase in apoptosis: that is where enosf $1 b$ expression is 
low enough to be affected by morpholino knockdown. Cells with decreased enosf $1 b$ cannot survive and die.

\section{Conclusions}

Given the recent publications identifying hsENOSF1 $\beta$ expression as a risk factor in at least two human cancers $[28,64]$, developing an in vivo animal model of ENOSF1 $\beta$ takes on added importance. The results of the WISH study presented here represent the first time a vertebrate ENOSF1 $\beta$ has been visualized in an intact model organism. The results of the mRNA and morpholino experiments are the first overexpression and knockdown phenotypes reported for a vertebrate ENOSF1 $\beta$. One of our major findings, increased apoptosis following in vivo ENOSF1 knockdown, has implications for cancer therapy. Given the results of the clinical studies of $[28,64]$ and in vitro cell culture data [23-27,62,65], it is not unreasonable to hypothesize that targeting ENOSF1 catalytic activity or possible interactions with other proteins may lead to increased apoptosis in tumours.

\section{Methods}

\section{Phylogenetics and bioinformatics}

BLASTP [66-68], used within NCBI map viewer [68] and Ensembl genome browser [69], was used to find the protein sequences of vertebrate homologues of hsENOSF $1 \beta$ in the latest genome version available. Ensembl genome browser was used to locate the chromosomal location of enosf $1 b$, and to identify exon/intron boundaries [69]. Top scoring BLAST hits were used to search the Zebrafish Gene Collection (ZGC, [70]) full length clone library. The hsENOSF1 $\beta$ sequence, [Genbank: NP_059982.2], was used to search the Protein Data Bank [34] for homologues with known function. The program bl2seq was used to calculate percent identity [67,71]. MUSCLE (2 iterations, CLUSTALW output) was used to align nucleotide and protein sequences and to generate phylogenetic trees [72]. JalView was used to visualize alignments [73]. NEBCutter was used to plan subcloning experiments [74].

\section{Zebrafish husbandry}

Zebrafish were maintained and used following approved NHGRI ACUC protocols. Adult wild type zebrafish (EK strain) and p53-/- mutant zebrafish [35] were maintained in a recirculating aquaculture system at $28.5^{\circ} \mathrm{C}$ and a 14:10 light:dark cycle per Westerfield [75]. Single adults were separated with plastic dividers in individual pair breeding boxes (Dura-Cross, LPS Inc. Rochester NY) the night before spawning. At first light, the divider was pulled and the adults were allowed to spawn naturally. Eggs were manually separated from the adults, rinsed free of faeces and debris, and raised at $28.5^{\circ} \mathrm{C}$ in embryo media $(480 \mathrm{mg}$ Instant Ocean salts, $16 \mathrm{~mL}$
$100 \% \mathrm{v} / \mathrm{v}$ methylene blue, $8 \mathrm{~L}$ system water, [75]) until they reached the desired stage.

\section{Whole mount In Situ Hybridization (WISH)}

A ZGC cDNA clone corresponding to a truncated zebrafish homologue of human ENOSF1 $\beta$ (enosf1b) in the vector pME18S-FL ( $p$-enosf1b) was purchased from a commercial supplier (OPEN Biosystems, Hunstville, AL). Following confirmatory sequencing in the NHGRI zebrafish core, MUSCLE alignment of this sequence to the identified full length zebrafish homologue of hsENOSF $1 \beta$ showed that the 3 ' end of this clone contained multiple gaps of non-existent homology and a polyA tail. As multiple regions with gaps and polyA tails are not conducive to successful WISH [50], a fragment of the clone with better homology to the 5' end of enosf $1 b$ was created. The XhoI-EcoRV fragment (532 bp) of penosf $1 b$ was subcloned into pBluescript SK(-) producing the plasmid used to make enosf $1 b$ riboprobe: pBSenosf1b-5' (see Additional File 6 for MUSCLE alignments illustrating this process). Plasmids containing sequences for no tail [54] and $P a x 2 a$ [55] were kind gifts of Dr. Milton English (NIH, National Eye Institute). Linearized plasmids were used to generate antisense or sense digoxigenin (DIG)-labelled riboprobes using T3 or T7 polymerase RNA labelling kits (Roche, Indianapolis, IN). Riboprobes were purified free of salts and enzymes using a Megaclear kit (Ambion, Austin TX). Embryos were staged according to Kimmel et al [76] and fixed in $4 \%$ paraformaldehyde in PBS overnight (4\% PFA/PBS) at $4^{\circ} \mathrm{C}$. Embryos younger than 24 hours post fertilization (hpf) were manually dechorionated with watchmaker forceps after fixation. All reagents for the WISH procedure were purchased from Sigma. WISH was performed as in Thisse and Thisse [50].

\section{Morpholino (MO) antisense oligonucleotide design}

MOs were purchased as lyophilized powders from GeneTools (Philomath, Oregon). In addition to the FITCtagged standard control MO (abbreviated here as "std ctrl,", see [77]), two MOs that target different evolutionarily conserved regions of the enosf $1 b$ transcript or pre-mRNA were also obtained (Table 2). The FITCtagged MO designated "ATG" targets the conserved ATG in exon 2 of the processed enosf $1 b$ transcript. The FITC-tagged MO designated "e10i10" targets the

Table 2 Morpholino antisense oligonucleotide (MO) sequences used in this study.

\begin{tabular}{cc}
\hline Name & Mo sequence \\
\hline Standard Control $($ std ctrl) & CCTCTTACCTCAGTTACAATTATA \\
\hline e10i10 & GTTACCTTAGAGATGGAAGCATGA \\
\hline ATG2 & CAGAATAATCTGGATCTGTGTGTGCAT \\
\hline
\end{tabular}


exon10-intron10 splice junction (e10i10) in enosf1b premRNA. Exon 10 was chosen for targeting by spliceblocking MO because it contains 3 conserved residues necessary for catalysis in other members of the MR family. Alignments of the protein products of the conserved regions targeted by the two morpholinos can be found in Additional file 5. Morpholino sequences (Table 2) were in silico tested for specificity by using the BLASTN program $[67,71]$ to search for alternative targets in the zebrafish genome. Morpholinos were resuspended in RNase-free water and quantified using a NanoDrop ND-1000 (Thermo Scientific) following quantification instructions. Immediately before use, diluted MOs were heated at $65^{\circ} \mathrm{C}$ for 10 minutes. Diluted MOs were then stored at room temperature until injected.

\section{RT-PCR}

Twenty zebrafish embryos each at the following stages: 1-8 cell, $25-50 \%$ epiboly, 5-20 somites, $24-48 \mathrm{hpf}$, and 72-96 hpf were dechorionated in pronase when needed and anesthetized in Tricaine per Westerfield [75]. Embryos were rinsed 3 times in sterile phosphate buffered saline (PBS), drained of all residual PBS, snap frozen in liquid nitrogen, and stored at $-80^{\circ} \mathrm{C}$. To assay developmental expression of enosf $1 b$, staged embryos were thawed on ice, homogenized in Trizol (Invitrogen, Carlsbad CA), and total RNA purified per Trizol package instructions. Total RNA $(1 \mu \mathrm{g})$ was used to prepare cDNA using a SuperScript III kit (also Invitrogen). Full length protein coding sequence of the zebrafish homologue of hsENOSF1 was PCR-amplified ("Full length" primers in Table 1) using AmpliTaq DNA polymerase (Applied Biosystems, Foster City CA) and a step down PCR protocol: $94^{\circ} \mathrm{C}, 10$ minutes; 40 cycles of $94^{\circ} \mathrm{C} / 30 \mathrm{~s}$, $62^{\circ} \mathrm{C} / 30 \mathrm{~s}, 72^{\circ} \mathrm{C} / 60 \mathrm{~s}$ (annealing temperature was decreased $0.5^{\circ} \mathrm{C} /$ cycle the first 7 cycles to a final annealing temperature of $58^{\circ} \mathrm{C}$ ); $72^{\circ} \mathrm{C}$ for $60 \mathrm{~s}$. To clone full length enosf $1 b$ for construction of an in vitro transcription vector, full length protein coding sequence of enosf $1 b$ was PCR amplified using a proof-reading polymerase (Platinum Pfx, Invitrogen) and primers designed to add a 5' XhoI site, a Kozak sequence, and a 3' SacII site to the PCR product (primer sequences in Table 1, PCR conditions same as above). To quantify mis-spliced enosf1b following e10i10 MO injection, single standard control injected or e10i10 MO-injected embryos were processed to total cDNA using a scaled down version of the Trizol protocol outlined above. Primers flanking enosf $1 b$ exon 10 (Table 1) were used in PCRs on the same samples [78]. Twenty percent of PCR reactions were run on precast $1 \%$ Tris-Borate-EDTA agarose gels containing ethidium bromide. Gels were photographed under UV light. Mis-spliced exon 10 PCR products were sequenced in the NHGRI zebrafish core.

\section{In vitro transcription of capped EGFP-polyA and enosf1b- EGFP-polyA mRNA}

Following digestion with XhoI and SacII, enosf1b was ligated into pEGFP-N1 previously digested with XhoI and SacII, generating enosf $1 b$ fused in frame to the Nterminus of EGFP (p-enosf1b-N1-EGFP). P-enosf1b-N1EGFP was sequenced in the NHGRI zebrafish core to verify that enosf $1 b$ was being amplified and for absence of PCR-induced mutations (sequencing data available upon request). The NheI/NotI fragment of p-enosfibN1-EGFP was subcloned downstream of the T7 promoter of pcDNA3.1(-) ( $p c D N A 3.1$-enosf1b-EGFP-polyA). The NheI/NotI fragment of pEGFP-N1 was also subcloned downstream of the T7 promoter of pcDNA3.1(-) (pcDNA3.1-EGFP-polyA).

Both pcDNA3.1-EGFP-polyA and pcDNA3.1-enosf1bEGFP-polyA were linearized 3' of the polyadenylation signal sequence and phenol/chloroform extracted to remove restriction enzyme. The linearized plasmids were then ethanol precipitated (post-digest cleanup per [51]), resuspended in nuclease-free $\mathrm{H}_{2} \mathrm{O}$, and used as templates for in vitro transcription (mMessage mMachine T7 Ultra in vitro transcription kit (Ambion, Austin TX)). Transcribed mRNA was phenol/chloroform extracted [78] and quantified on an ND-1000 Nanodrop spectrophotometer (Thermo Scientific). The mRNA was ethanol precipitated [78], resuspended in nuclease-free $\mathrm{H}_{2} \mathrm{O}$, and stored in aliquots at $-80^{\circ} \mathrm{C}$ until use.

\section{Embryo microinjection}

Glass capillaries (World Precision Instruments, $1 \mathrm{~mm}$ inside diameter with filament) were pulled on a Kopf 730 vertical capillary puller. Using a sequencing gel loading pipette tip, capillaries were back-filled with enosf1b-GFP or GFP mRNA. Pulled capillaries were broken to a narrow tip with a razor blade under a stereomicroscope, calibrated in mineral oil [51], and used to inject $0.4 \mathrm{~nL}$ pulses of in vitro transcribed mRNA into the blastomeres of 1-2 cell embryos. The same procedure was used to prepare MO injection capillaries. For MO injection, the injection volume was adjusted to 1.4 $\mathrm{nL}$ and the injection target was the cytoplasmic streamers immediately ventral to the blastomeres of 1-2 cell embryos. Coinjections for rescue experiments used the injection volume for mRNA injection. Concentrations of stock mRNA and stock MOs were adjusted to achieve the final concentrations listed in Results above. Following microinjection, embryos were raised at $28.5^{\circ} \mathrm{C}$ and periodically photographed using a Leica MZ16F stereomicroscope with GFP epifluorescence optics. 


\section{Scoring microinjection phenotypes and statistics}

Fluorescence of EGFP and enosf1b-EGFP mRNAinjected embryos was scored at tailbud stage the night of the day of injection. GFP-negative embryos in injected clutches were discarded. GFP was assessed and stage was scored for surviving embryos at 24 and $48 \mathrm{hpf}$.

FITC-negative embryos in MO-injected clutches were discarded the night of injection. FITC-positive embryos were scored for MO-induced phenotypes daily until there were no surviving embryos (usually $48 \mathrm{hpf}$ ). "ATG phenotype" was defined as decreased anterior-posterior axis, severe notochord kinks and pericardial edema. "E10i10 phenotype" was defined as mild to severe notochord kinks and pericardial edema. Because the FITCtagged MO masked the GFP signal, coinjection and MO-injected embryos were both treated as MO-injected the first day: fluorescence-negative embryos were discarded the night of the injection. Control mRNAinjected embryos were scored as described above. Percentage embryos in each clutch were scored for MOinduced phenotype using the criteria described above. All data values shown in the figures below are the average of three experiments with standard deviation bars. Total " $n$ " values are the totals of the three independent experiments. When necessary, two-tailed Student's t test was used to calculate $\mathrm{p}$ values. All statistics and tests were calculated in Microsoft Excel.

\section{Whole mount TUNEL assay}

The protocol used is modified from the package instructions of the Apoptag TUNEL kit (Chemicon, see also: $[56,57])$. Fixed 36 hpf embryos, in microcentrifuge tubes, were gradually dehydrated in five minute room temperature (RT) washes of $25 \%, 50 \%, 75 \%$, ethanol/ PBS. After two $100 \%$ ethanol washes, the embryos were stored overnight at $-20^{\circ} \mathrm{C}$. Embryos were then rehydrated to PBT (1X PBS, $0.1 \%$ Tween 20) by reversing the order of the washes above. Embryos were washed an additional 2 times in 100\% PBT and then bleached in $3 \%$ peroxide in PBT for 10 minutes at RT. After bleaching, embryos were washed in PBT 3 times for $10 \mathrm{~min}$ utes each at RT. Embryos were then permeabilized by adding $5 \mathrm{uL}$ of $2 \mathrm{mg} / \mathrm{mL}$ proteinase $\mathrm{K}$ to the final PBT wash (final volume $1 \mathrm{~mL}$ ) and incubating for 10 minutes at RT. Proteinase $\mathrm{K}$ was aspirated and permeabilized embryos were washed twice in PBT (7 minutes at RT) and then post-fixed in $4 \%$ PFA/PBS for 15 minutes at RT. Trace amounts of PFA were removed by exhaustive PBT washes (five - five minute washes at RT). While washing in PBT, Apoptag equilibration and reaction buffers were thawed. Working enzyme solution was made $(154 \mu \mathrm{L}$ reaction buffer $+66 \mu \mathrm{L}$ enzyme per tube assayed). The last of the 5 PBT washes was aspirated and replaced with equilibration buffer for 20 minutes at
RT. Equilibration buffer was removed and replaced with working enzyme solution (50-100 $\mu \mathrm{L}$ of liquid per 20 embryos). Embryos in working enzyme solution were incubated on a heat block at $37^{\circ} \mathrm{C}$ for 60 minutes with 300 RPM agitation. While incubating in enzyme, Apoptag Stop/Wash concentrate was thawed and diluted to working Stop/Wash solution (1 $\mathrm{mL}$ concentrate +34 $\mathrm{mL} \mathrm{dd}_{2} \mathrm{O}$ ). Enzyme was removed and replaced with 1 $\mathrm{mL}$ of diluted Stop/Wash solution. Embryos were incubated in Stop/Wash solution at RT for 60 minutes with agitation. Stop/Wash solution was then washed off in 3 10 minute PBT washes with agitation. The last wash was aspirated and replaced with anti-DIG horseradish peroxidase conjugated monoclonal antibody (provided in the Apoptag kit) diluted 1:9,000 in blocking buffer (2\% Roche blocking reagent, $10 \%$ lamb serum, and $1 \%$ DMSO in $\mathrm{ddH}_{2} \mathrm{O}$ ). Embryos were incubated in anti-DIG antibody overnight at $4{ }^{\circ} \mathrm{C}$. Antibody was removed and embryos were washed 4 times in PBT for 10 minutes at RT. Washed embryos were stained in Tris-buffered DAB, (3,3'-Diaminobenzidine: SigmaFast, Sigma-Aldrich) for 5 minutes at RT in the dark. Immediately after staining, embryos were fixed in $4 \%$ PFA/PBS. Tails of TUNEL-stained embryos were photographed as described for WISH above. TUNEL-positive spots above the yolk sac extension (YSE) were counted for 3 embryos from each condition. Statistics were performed as above.

Whole mount phosphohistone-H3 (pH3) antibody staining PH3 staining protocol was developed from the protocol of [57]. Embryos (36 hpf) were fixed in 4\% PFA/PBS as above. Following fixation, PFA/PBS was aspirated and embryos were incubated in ice cold acetone for seven minutes, followed by a brief rinse in $\mathrm{dd}_{2} \mathrm{O}$. Embryos were then washed in PBT (1X PBS, 0.1\% Tween 20) two times for five minutes at RT. The last PBT wash was aspirated and replaced with blocking buffer (2\% Roche blocking reagent, $10 \%$ lamb serum, and 1\% DMSO in $\mathrm{ddH}_{2} \mathrm{O}$ ). Embryos were blocked for 30 minutes at RT. While blocking, rabbit anti-pH3 polyclonal antibody (Santa Cruz Biotechnology) was diluted 1:200 in blocking buffer. After blocking, embryos were incubated in diluted anti-pH3 antibody overnight at $4{ }^{\circ} \mathrm{C}$. Antibody in blocking buffer was aspirated and embryos were washed in 415 minute PBT washes at RT. While washing, goat anti-rabbit HRP conjugated secondary antibody was diluted 1:1000 in blocking buffer. The last wash was aspirated and embryos were incubated in diluted antirabbit secondary antibody for two hours at RT with gentle agitation. Secondary antibody was aspirated and embryos were washed in 415 minute PBT washes at RT. Embryos were then stained in DAB, fixed in PFA, and photographed as described above for WISH. PH3- 
positive spots above the YSE were counted for 3 embryos from each condition. Statistics were performed as above.

\section{Additional material}

Additional file 1: Protein sequences used in phylogenetic analysis $\mathrm{NCBI}$ or Ensembl accession numbers follow genus numbers. FuCD is fuconate dehydratase of Xanthomonas.

Additional file 2: Alignment of protein sequences used in phylogenetic analysis. Alignment done in MUSCLE.

Additional file 3: Protein sequences of predicted ENOSF1 $\beta$ s with missing exons and not used in phylogenetic analysis. Ensembl accession numbers follow the genus name.

Additional file 4: E10i10-injected embryos express enosf1b transcript with inserted intron 10 . Sequence of mis-spliced product generated from e10i10-injected embryo CDNA and PCR with exon 10 flanking primers. Exons and introns are color-coded.

Additional file 5: Alignments of conserved regions targeted by morpholino antisense oligonucleotides used in this study. Alignment done in MUSCLE.

Additional file 6: Creating the enosf1b WISH plasmid. Sequences of enosfib in plasmids p-enosfib (Additional figure 1) and pBS-enosf1b-5' (Additional figure 2). See Methods for rationale.

\section{Acknowledgements}

Barbara Foster, Mike Moser, Jason Kirk, and Avinash Srivatsan provided critical evaluation at multiple points during the conception and development stages of this study. We also thank Colleen Kane, Kevin Bishop, and other members of the Dolnick, Sufrin, and Liu Labs for helpful discussions. This work was supported in part by The Intramural Program of the National Human Genome Research Institute, NIH.

\section{Author details}

'Oncogenesis and Development Section, National Human Genome Research Institute, 49 Convent Drive, Bethesda MD, 20892, USA. ${ }^{2}$ Program of Molecular Pharmacology and Cancer Therapeutics, Roswell Park Graduate Division, State University of New York at Buffalo, Elm and Carlton Streets, Buffalo NY, 14263, USA. ${ }^{3}$ Zebrafish Core, National Human Genome Research Institute, 49 Convent Drive, Bethesda MD, 20892, USA. ${ }^{4}$ Department of Molecular and Cellular Biology, Roswell Park Cancer Institute, Elm and Carlton Streets, Buffalo NY, 14263, USA. ${ }^{5}$ Department of Pharmacology and Therapeutics, Roswell Park Cancer Institute, Elm and Carlton Streets, Buffalo NY, 14263, USA.

\section{Authors' contributions}

SF performed bioinformatics and phylogenetics studies. SF and PJK carried out WISH experiments. SF did embryo microinjection experiments, TUNEL and $\mathrm{pH} 3$ staining, and performed statistics. RS and SF designed morpholino sequences and oligonucleotide sequences used as primers. RS planned and guided sequencing experiments. BC performed sequencing experiments. SF, $K G, B D, R S, J S$, and PL conceived of the study and participated in the design of the study and helped to draft the manuscript. All authors approved the final manuscript.

\section{Competing interests}

The authors declare that they have no competing interests.

Received: 4 July 2011 Accepted: 26 September 2011

Published: 26 September 2011

\section{References}

1. Dayhoff MO: Computer-Analysis of Protein Sequences. Federation Proceedings 1974, 33:2314-2316
2. Dayhoff MO: Origin and Evolution of Protein Superfamilies. Federation Proceedings 1976, 35:2132-2138.

3. Dayhoff MO, McLaughlin PJ, Barker WC, Hunt LT: Evolution of Sequences within Protein Superfamilies. Naturwissenschaften 1975, 62:154-161.

4. Gerlt JA, Babbitt PC, Rayment I: Divergent evolution in the enolase superfamily: the interplay of mechanism and specificity. Archives of Biochemistry and Biophysics 2005, 433:59-70.

5. Andreeva A, Howorth D, Chandonia JM, Brenner SE, Hubbard TJP, Chothia C, Murzin AG: Data growth and its impact on the SCOP database: new developments. Nucleic Acids Research 2008, 36:D419-D425.

6. Greene LH, Lewis TE, Addou S, Cuff A, Dallman T, Dibley M, Redfern O, Pearl F, Nambudiry R, Reid A, et al: The CATH domain structure database: new protocols and classification levels give a more comprehensive resource for exploring evolution. Nucleic Acids Research 2007, 35 D291-D297.

7. Babbitt PC, Hasson MS, Wedekind JE, Palmer DRJ, Barrett WC, Reed GH, Rayment I, Ringe D, Kenyon GL, Gerlt JA: The enolase superfamily: A general strategy for enzyme-catalyzed abstraction of the alpha-protons of carboxylic acids. Biochemistry 1996, 35:16489-16501.

8. Pancholi V: Multifunctional alpha-enolase: its role in diseases. Cellular and Molecular Life Sciences 2001, 58:902-920.

9. Rakus JF, Fedorov AA, Fedorov EV, Glasner ME, Hubbard BK, Delli JD, Babbitt PC, Almo SC, Gerlt JA: Evolution of enzymatic activities in the enolase superfamily: L-rhamnonate dehydratase. Biochemistry 2008, 47:9944-9954.

10. Rakus JF, Fedorov AA, Fedorov EV, Glasner ME, Vick JE, Babbitt PC, Almo SC, Gerlt JA: Evolution of enzymatic activities in the enolase superfamily: DMannonate dehydratase from Novosphingobium aromaticivorans. Biochemistry 2007, 46:12896-12908.

11. Yew WS, Fedorov AA, Fedorov EV, Almo SC, Gerlt JA: Evolution of enzymatic activities in the enolase superfamily: L-talarate/galactarate dehydratase from Salmonella typhimurium LT2. Biochemistry 2007, 46:9564-9577.

12. Yew WS, Fedorov AA, Fedorov EV, Rakus JF, Pierce RW, Almo SC, Gerlt JA: Evolution of enzymatic activities in the enolase superfamily: L-fuconate dehydratase from Xanthomonas campestris. Biochemistry 2006, 45:14582-14597.

13. Yew WS, Fedorov AA, Fedorov EV, Wood BM, Almo SC, Gerlt JA: Evolution of enzymatic activities in the enolase superfamily: D-tartrate dehydratase from Bradyrhizobium japonicum. Biochemistry 2006, 45:14598-14608.

14. Gulick AM, Hubbard BK, Gerlt JA, Rayment I: Evolution of enzymatic activities in the enolase superfamily: Identification of the general acid catalyst in the active site of D-glucarate dehydratase from Escherichia coli. Biochemistry 2001, 40:10054-10062.

15. Gulick AM, Hubbard BK, Gerlt JA, Rayment I: Evolution of enzymatic activities in the enolase superfamily: Crystallographic and mutagenesis studies of the reaction catalyzed by D-glucarate dehydratase from Escherichia coli. Biochemistry 2000, 39:4590-4602.

16. Hubbard BK, Gulick AM, Babbitt PC, Rayment I, Gerlt JA: Evolution of enzymatic activities in the enolase superfamily: Mechanism, structure, and metabolic context of glucarate dehydratase from Escherichia coli. Faseb Journal 1999, 13:A1446-A1446.

17. Wieczorek SJ, Kalivoda KA, Clifton JG, Ringe D, Petsko GA, Gerlt JA: Evolution of enzymatic activities in the enolase superfamily: Identification of a "new" general acid catalyst in the active site of Dgalactonate dehydratase from Escherichia coli. Journal of the American Chemical Society 1999, 121:4540-4541.

18. Palmer DRJ, Hubbard BK, Gerlt JA: Evolution of enzymatic activities in the enolase superfamily: Partitioning of reactive intermediates by (D)glucarate dehydratase from Pseudomonas putida. Biochemistry 1998, 37:14350-14357.

19. Gulick AM, Palmer DRJ, Babbitt PC, Gerlt JA, Rayment I: Evolution of enzymatic activities in the enolase superfamily: Crystal structure of (D)glucarate dehydratase from Pseudomonas putida. Biochemistry 1998, 37:14358-14368.

20. Hubbard BK, Koch M, Palmer DRJ, Babbitt PC, Gerlt JA: Evolution of enzymatic activities in the enolase superfamily: Characterization of the (D)-glucarate/galactarate catabolic pathway in Escherichia coli. Biochemistry 1998, 37:14369-14375. 
21. Watanabe S, Saimura M, Makino K: Eukaryotic and bacterial gene clusters related to an alternative pathway of nonphosphorylated L-rhamnose metabolism. Journal of Biological Chemistry 2008, 283:20372-20382.

22. Crystal structure of rhamnonate dehydratase from Gibberella zeae complexed with Mg. [http://www.pdb.org/pdb/explore/explore.do? structureld=3FXG].

23. Liang P, Nair JR, Song L, McGuire JJ, Dolnick BJ: Comparative genomic analysis reveals a novel mitochondrial isoform of human rTS protein and unusual phylogenetic distribution of the rTS gene. Bmc Genomics 2005, 6.

24. Dolnick BJ, Lu K, Yin MB, Rustum YM: Recent advances in the study of rTS proteins. rTS expression during growth and in response to thymidylate synthase inhibitors in human tumor cells. In Advances in Enzyme Regulation Edited by: Weber G 1997, 37:95-109, Advances in Enzyme Regulation.

25. Black AR, Dolnick BJ: Expression of rTS correlates with altered growth regulation of thymidylate synthase. Cancer Research 1996, 56:700-705.

26. Dolnick BJ, Black AR, Winkler PM, Schindler $K$, Hsueh CT: rTS gene expression is associated with altered cell sensitivity to thymidylate synthase inhibitors. In Advances in Enzyme Regulation Edited by: Weber G 1996, 36:165-180, Advances in Enzyme Regulation.

27. Dolnick BJ, Black AR: Alternate splicing of the rTS gene product and its overexpression in a 5-fluorouracil-resistant cell line. Cancer Research 1996, 56:3207-3210.

28. Kuo SJ, Wang HC, Chow KC, Chiou SH, Chiang SF, Lin TY, Chiang IP, Chen DR: Expression of rTS $\beta$ beta as a 5-fluorouracil resistance marker in patients with primary breast cancer. Oncology Reports 2008, 19:881-888.

29. Lin YL, Chow KC: rTS beta as a Novel 5-fluorouracil Resistance Marker of Colorectal Cancer: A Preliminary Study. Annals Academy of Medicine Singapore 2010, 39:107-111.

30. Burgess S: New techniques for using zebrafish as a model for development. Methods 2006, 39:181-182.

31. Traver D, Herbomel P, Patton EE, Murphey RD, Yoder JA, Litman GW, Catic A, Amemiya CT, Zon LI, Trede NS: The zebrafish as a model organism to study development of the immune system. Advances in Immunology, Vol 81 2003, 81:253-+.

32. Lohr JL, Yost J: Vertebrate model systems in the study of early heart development: Xenopus and zebrafish. American Journal of Medical Genetics 2000, 97:248-257.

33. Kelly GM: Zebrafish: a model system for elucidating the mechanisms of development. Biochemistry and Cell Biology-Biochimie Et Biologie Cellulaire 1997, 75:U3-U3.

34. Bernstein FC, Koetzle TF, Williams GJB, Meyer EF, Brice MD, Rodgers JR, Kennard O, Shimanouchi T, Tasumi M: Protein data bank - computerbased archival file for macromolecular structures. Archives of Biochemistry and Biophysics 1978, 185:584-591.

35. Berghmans S, Murphey RD, Wienholds E, Neuberg D, Kutok JL, Fletcher CDM, Morris JP, Liu TX, Schulte-Merker S, Kanki JP, et al: tp53 mutant zebrafish develop malignant peripheral nerve sheath tumors. Proceedings of the National Academy of Sciences of the United States of America 2005, 102:407-412.

36. Carroll RH: Vertebrate Paleontology and Evolution New York: W.H. Freeman and Co; 1988.

37. Gnathostomata Jawed Vertebrates. [http://tolweb.org/Gnathostomata/ 14843].

38. Janvier P: The dawn of the vertebrates: Characters versus common ascent in the rise of current vertebrate phylogenies. Palaeontology 1996 39:259-287.

39. Dehal P, Satou Y, Campbell RK, Chapman J, Degnan B, De Tomaso A, Davidson B, Di Gregorio A, Gelpke M, Goodstein DM, et al: The draft genome of Ciona intestinalis: Insights into chordate and vertebrate origins. Science 2002, 298:2157-2167.

40. Forey $P$, Janvier P: Agnathans and the Origin of Jawed Vertebrates. Nature 1993, 361:129-134.

41. Koepfli K, Wayne R, Springer M, Amrine-Madsen H: A new phylogenetic marker, apolipoprotein B, provides compelling evidence for eutherian relationships. Molecular Phylogenetics and Evolution 2003, 28:225-240.

42. Gissi C, Pesole G, Saccone C, Arnason U, Derchia A: The guinea-pig is not a rodent. Nature 1996, 381:597-600.

43. Huchon D, Douzery E: Rabbits, if anything, are likely Glires. Molecular Phylogenetics and Evolution 2004, 33:922-935.
44. He J, Irwin DM, Chen R, Zhang YP: Stepwise loss of motilin and its specific receptor genes in rodents. Journal of Molecular Endocrinology 2010, 44:37-44

45. Demuth JP, De Bie T, Stajich JE, Cristianini N, Hahn MW: The Evolution of Mammalian Gene Families. Plos One 2006, 1.

46. Flintoft $\mathrm{L}$, Skipper M: Model organisms - Xenopus tropicalis goes genetic. Nature Reviews Genetics 2006, 7:588-589.

47. Cleaver O, Krieg PA: Notochord patterning of the endoderm. Developmental Biology 2001, 234:1-12.

48. Kim SK, Hebrok M, Melton DA: Notochord to endoderm signaling is required for pancreas development. Development 1997, 124:4243-4252.

49. Stemple DL: Structure and function of the notochord: an essential organ for chordate development. Development 2005, 132:2503-2512.

50. Thisse C, Thisse B: High-resolution in situ hybridization to whole-mount zebrafish embryos. Nature Protocols 2008, 3:59-69.

51. Gilmour DT, Jessen JR, Lin S: Manipulating Gene Expression in Zebrafish. In Zebrafish: A Practical Approach. Edited by: Nusslein-Volhard C, Dahm R. New York: Oxford University Press; 2002:121-144.

52. Hammerschmidt M, Blader P, Strahle U: Strategies to Perturb Zebrafish Development. In The Zebrafish: Biology. Edited by: Detrich HW, Westerfield M, Zon LI. New York: Academic Press; 1999:

53. Robu ME, Larson JD, Nasevicius A, Beiraghi S, Brenner C, Farber SA, Ekker SC: p53 activation by knockdown technologies. PLoS Genet 2007 3:787-801.

54. Schultemerker S, Vaneeden FJM, Halpern ME, Kimmel CB, Nussleinvolhard C No Tail (Ntl) Is the Zebrafish Homolog of the Mouse-T (Brachyury) Gene. Development 1994, 120:1009-1015.

55. Krauss S, Johansen T, Korzh V, Moens U, Ericson JU, Fjose A: Zebrafish Pax [Zf-a] - a Paired Box-Containing Gene Expressed in the Neural-Tube. Embo J 1991, 10:3609-3619.

56. Webb AE, Kimelman D: Analysis of Early Epidermal Development in Zebrafish. 2004, 289:137-145.

57. Shepard JL, Amatruda JF, Stern HM, Subramanian A, Finkelstein D, Ziai J, Finley KR, Pfaff KL, Hersey C, Zhou Y, et al: Zebrafish bmyb mutation causes genome instability and increased cancer susceptibility. Proceedings of the National Academy of Sciences of the United States of America 2005, 102:13194-13199.

58. Hector S, Prehn JHM: Apoptosis signaling proteins as prognostic biomarkers in colorectal cancer: A review. Biochimica Et Biophysica ActaReviews on Cancer 2009, 1795:117-129.

59. Singhal S, Vachani A, Antin-Ozerkis D, Kaiser LR, Albelda SM: Prognostic implications of cell cycle, apoptosis, and angiogenesis biomarkers in non-small cell lung cancer: A review. Clinical Cancer Research 2005 11:3974-3986.

60. Wang GD, Reed E, Li QDQ: Apoptosis in prostate cancer: Progressive and therapeutic implications (Review). International Journal of Molecular Medicine 2004, 14:23-34.

61. Shivapurkar N, Reddy J, Chaudhary PM, Gazdar AF: Apoptosis and lung cancer: A review. Journal of Cellular Biochemistry 2003, 88:885-898.

62. Dolnick BJ, Angelino NJ, Dolnick R, Sufrin JR: A novel function for the rTS gene. Cancer Biology \& Therapy 2003, 2:364-369.

63. Dodd J, Jessell TM, Placzek M: NEUROSCIENCE:The When and Where of Floor Plate Induction. Book NEUROSCIENCE:The When and Where of Floor Plate Induction 282:1654-1657, (Editor ed.^eds.) City; 1998: 1654-1657.

64. Lin YL, Chow KC: rTS beta as a Novel 5-fluorouracil Resistance Marker of Colorectal Cancer: A Preliminary Study. Annals Academy of Medicine Singapore 39:107-111.

65. Dolnick BJ: Cloning and Characterization of a Naturally-Occurring Antisense Rna to Human Thymidylate Synthase Messenger-Rna. Nucleic Acids Research 1993, 21:1747-1752.

66. Altschul SF, Madden TL, Schaffer AA, Zhang JH, Zhang Z, Miller W, Lipman DJ: Gapped BLAST and PSI-BLAST: a new generation of protein database search programs. Nucleic Acids Research 1997, 25:3389-3402.

67. Johnson M, Zaretskaya I, Raytselis Y, Merezhuk Y, McGinnis S, Madden TL: NCBI BLAST: a better web interface. Nucleic Acids Research 2008, 36: W5-W9.

68. Sayers EW, Barrett T, Benson DA, Bolton E, Bryant SH, Canese K, Chetvernin V, Church DM, DiCuccio M, Federhen S, et al: Database resources of the National Center for Biotechnology Information. Nucleic Acids Research 2011, 39:D38-D51. 
69. Spudich GM, Fernandez-Suarez XM: Touring Ensembl: A practical guide to genome browsing. Bmc Genomics 2010, 11

70. Rasooly RS, Henken D, Freeman N, Tompkins L, Badman D, Briggs J, Hewitt AT, Natl Inst HIth Trans NIHZ: Genetic and genomic tools for zebrafish research: The NIH zebrafish initiative. Developmental Dynamics 2003, 228:490-496

71. Ye J, McGinnis S, Madden TL: BLAST: improvements for better sequence analysis. Nucleic Acids Research 2006, 34:W6-W9.

72. Edgar RC: MUSCLE: multiple sequence alignment with high accuracy and high throughput. Nucleic Acids Research 2004, 32:1792-1797.

73. Waterhouse AM, Procter JB, Martin DMA, Clamp M, Barton GJ: Jalview Version 2-a multiple sequence alignment editor and analysis workbench. Bioinformatics 2009, 25:1189-1191.

74. Vincze T, Posfai J, Roberts RJ: NEBcutter: a program to cleave DNA with restriction enzymes. Nucleic Acids Research 2003, 31:3688-3691.

75. Westerfield M: The zebrafish book. A guide for the laboratory use of zebrafish (Danio rerio). 4 edition. Eugene.: Univ. of Oregon Press; 2000.

76. Kimmel CB, Ballard WW, Kimmel SR, Ullmann B, Schilling TF: Stages of Embryonic-Development of the Zebrafish. Developmental Dynamics 1995, 203:253-310.

77. Eisen JS, Smith JC: Controlling morpholino experiments: don't stop making antisense. Development 2008, 135:1735-1743.

78. Sambrook J, Fritsch E, Maniatis T: Molecular Cloning: A Laboratory Manual Cold Spring Harbor, NY Cold Spring Harbor Laboratory Press; 1989.

doi:10.1186/2045-3701-1-32

Cite this article as: Finckbeiner et al:: Transient knockdown and overexpression reveal a developmental role for the zebrafish enosfib gene. Cell \& Bioscience 2011 1:32.

\section{Submit your next manuscript to BioMed Central and take full advantage of:}

- Convenient online submission

- Thorough peer review

- No space constraints or color figure charges

- Immediate publication on acceptance

- Inclusion in PubMed, CAS, Scopus and Google Scholar

- Research which is freely available for redistribution

Submit your manuscript at www.biomedcentral.com/submit 